\title{
Chiral Overpass Induction in Dynamic Helical Polymers Bearing Pendant Groups with Two Chiral Centers
}

Esteban Suárez-Picado, Emilio Quiñoá, Ricardo Riguera, Félix Freire

\section{Accepted Author Manuscript}

This is the peer reviewed version of the following article: E. Suárez-Picado, E. Quiñoá, R. Riguera, F. Freire, Angew. Chem. Int. Ed. 2020, 59, 4537, which has been published in final form at https:// doi.org/10.1002/anie.201915213. This article may be used for non-commercial purposes in accordance with Wiley Terms and Conditions for Use of Self-Archived Versions

\section{How to cite:}

E. Suárez-Picado, E. Quiñoá, R. Riguera, F. Freire, Angew. Chem. Int. Ed. 2020, 59, 4537

\section{Copyright information:}

(C) 2019 Wiley-VCH Verlag GmbH \& Co. KGaA, Weinheim. This article may be used for noncommercial purposes in accordance with Wiley Terms and Conditions for self-archiving 


\title{
Chiral Overpass-Induction in Dynamic Helical Polymers Bearing Pendant Groups with Two Chiral Centers
}

\author{
Esteban Suárez-Picado, Emilio Quiñoá, Ricardo Riguera and Félix Freire*
}

\author{
Centro Singular de investigación en Química Biolóxica e Materiais Moleculares (CiQUS) and Departamento de Química Orgánica \\ Universidade de Santiago de Compostela \\ E-15782 Santiago de Compostela, Spain \\ felix.freire@usc.es
}

\begin{abstract}
The dynamic behaviour of helical polymers bearing pendants with two chiral centers was studied. Controlled conformational changes at the chiral units placed either closer or further to the main chain promote different helical structures. Although the first residue is usually responsible for commanding a specific helicity $(P$ or $M)$, herein it was found that the second chiral center is also able to induce a preferred helical sense when is located spatially closer to the main chain, thereby cancelling the order from the first chiral moiety. This result is achieved through proper coordination with a metal cation. As proof of concept, PPAs that bear one and two chiral amino acid units of different sizes and configuration combinations ( $L / D$ alanine and $L / D$ phenylalanine) as pendants were evaluated. In total, ten polymers were studied. This result constitutes the first report of axial control from the remote stereocenter in polymers bearing complex stereopendants.
\end{abstract}

\section{Introduction}

In helical polymers, the helicity sense of the backbone is determined by the chirality of the pendant. ${ }^{[1-15]}$ Thus, for a certain helical polymer, $P$ or $M$ helical senses can be obtained switching the $R / S$ absolute configuration of the asymmetric center.

In the case of dynamic helical polymers, the helical sense control can be obtained by external stimuli ${ }^{[1-16]}$, which can alter the conformational composition of the pendant group, and as a result, producing changes in both helical sense and elongation of the scaffold. This stimuli-responsive behaviour of dynamic helical polymers has attracted the attention of the scientific community during the last years due to the potential applications of these materials in fields such as sensors, ${ }^{[7-9]}$ chiroptical switches, ${ }^{[10-12]}$ chiral stationary phase ${ }^{[16]}$ or chiral catalysts, ${ }^{[17-22]}$ among other applications.

In literature, it is found that helical polymers bearing pendant groups with more than one chiral center, the helical sense of the polymer is governed by the chiral moiety closer to the helical backbone. ${ }^{[23-25]}$ These studies unravel an important relationship between the orientation of the different substituents at the pendant group and the helical sense adopted by the helical polymer.

In this work we want to deepen the study of the dynamic behavior of helical polymers bearing more than one chiral residue. Specifically, we want to explore how conformational changes at the chiral residues placed closer or further to the main chain affect the helical sense of the polymer. Poly(phenylacetylene)s (PPAs) bearing amino acid or peptide residues as substituents generally adopt helical structures stabilized by hydrogen bonds between neighboring pendants $\mathrm{n}^{\text {th }}$ and $(\mathrm{n}+2)^{\text {th }}$ or $\mathrm{nth}$ and $(\mathrm{n}+3)^{\text {th }}$ - adopting a $\beta$-sheet like orientation. ${ }^{[25,26]}$ In such a case, the amide groups of the amino acids residues are antiperiplanar (anti, ap) oriented, placing the first chiral center closer to the polyene backbone, while the other chiral centers are placed further away. This fact clearly explains how the first chiral center of a peptide sequence commands the helical sense in multi-chiral PPAs (Figure 1). ${ }^{[27,28]}$

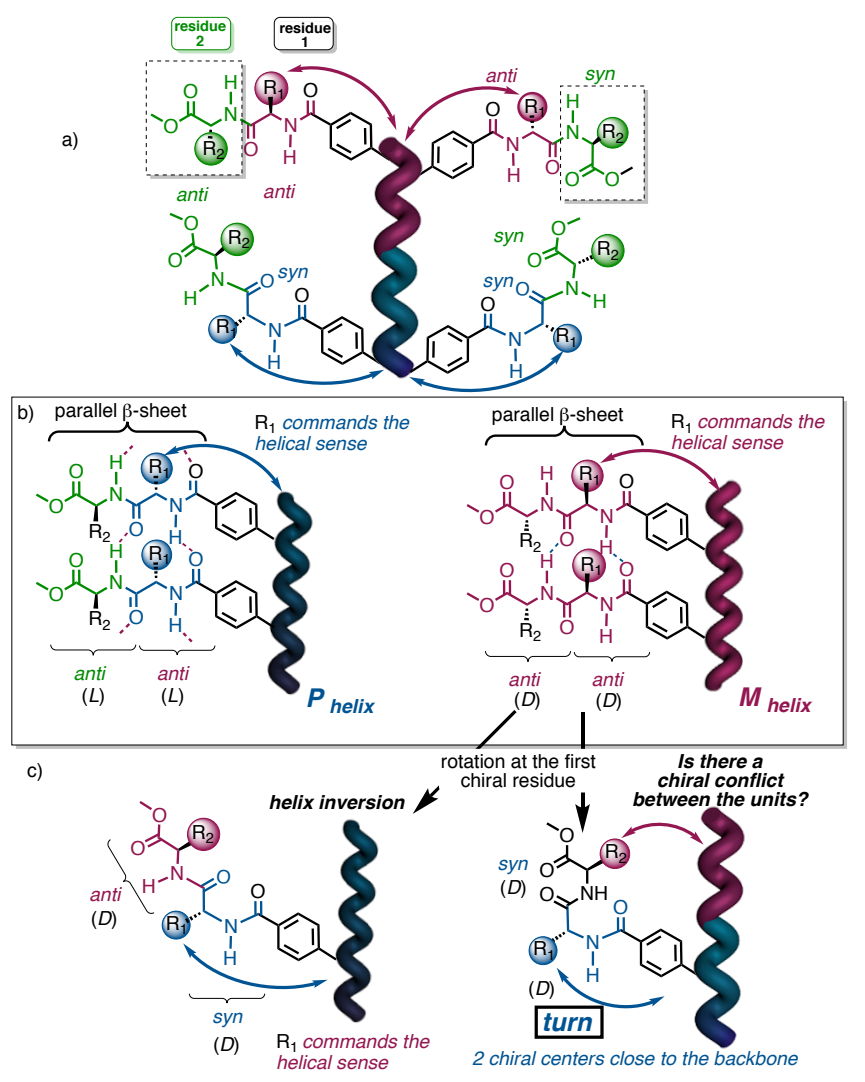

Figure 1. Conceptual representation of: (a) possible conformational changes at residue 1 and residue 2 , (b) a $\beta$-sheet arrangement between pendants and (c) expected helical structural effects by the presence of different conformers at residue 1 in a PPA bearing a dipeptide pendant group.

Interestingly, other structural motifs different than $\beta$-sheets are also found in literature related to PPAs bearing peptides with a single chiral residue as pendants. ${ }^{[30,31]}$ Thus, "turns" can be obtained due to rotation of the dihedral angle between amide residues, and a synperiplanar ( $s y n, s p)$ conformation between carbonyl groups is also possible. ${ }^{[32,33]}$ These conformational changes towards different structural motifs are usually produced by changes in the polarity of the solvent ${ }^{[9,34]}$ or by the addition of external stimuli such as metal ions and are accompanied always with changes in the helical structure of the polymer (elongation and/or helical sense). ${ }^{[35-41]}$ 


\section{Results and Discussion}

Herein, we want to study the helical sense control in PPAs bearing a chiral dipeptide pendant group with conformational changes in the two chiral residues.

To perform these studies, two different amino acids capped at the $C$ termini with a methyl ester group -alanine and phenylalanine - were chosen due to their different size. Alanine (Ala) is the smallest natural chiral amino acid, while phenylalanine (Phe) contains a large side chain (benzyl group). In our design, PPAs containing a single amino acid are necessary as control -poly-( $L$ )-Ala-OMe, (poly-1), and poly-( $L$ )Phe-OMe, (poly-6) - ${ }^{[39,41]}$ In addition, eight PPAs bearing dipeptides with different diastereomeric relationship are needed -poly-(L,L)-Ala-Ala-OMe, (poly-2); poly-(L,D)-Ala-Ala-OMe, (poly-3); poly-(L,L)-Ala-Phe-OMe, (poly-4); poly- $(L, D)-A l a-P h e-$ OMe, (poly-5); poly- $(L, L)-P h e-A l a-O M e,(p o l y-7)$; poly- $(L, D)-P h e-$ Ala-OMe, (poly-8); poly-(L,L)-Phe-Phe-OMe, (poly-9); poly- $(L, D)$ Phe-Phe-OMe, (poly-10) - to analyze how configuration and size of the different amino acids affect the helical structure of the PPA (Figure 2)

a)<smiles>C#Cc1ccc(C(=O)NC(C)C(=O)OC)cc1</smiles>
$\mathrm{m}-(L)-$ Ala-OMe (1)<smiles>C#Cc1ccc(C(=O)NC(C)C(=O)N[C@@H](C)C(=O)OC)cc1</smiles>

$\mathrm{m}-(L, L)-$ Ala-Ala-OMe (2)<smiles>C#Cc1ccc(C(=O)NC(C)C(=O)N[C@@H](C)C(=O)OC)cc1</smiles>

$\mathrm{m}-(L, D)$-Ala-Ala-OMe (3)<smiles>C#Cc1ccc(C(=O)NC(C)C(=O)N[C@@H](Cc2ccccc2)C(=O)OC)cc1</smiles>
$\mathrm{m}$-(L,D)-Phe-Ala-OMe (8)<smiles>C#Cc1ccc(C(=O)NC(CC(C)=CC)C(=O)N[C@@H](Cc2ccccc2)C(=O)OC)cc1</smiles>
$\mathrm{m}-(L, L)-\mathrm{Phe}-\mathrm{Phe}-\mathrm{OMe}(\mathbf{9})$<smiles>C#Cc1ccc(C(=O)NC(Cc2ccccc2)C(=O)N[C@@H](C)C(=O)OC)cc1</smiles><smiles>C#Cc1ccc(C(=O)N[C@@H](Cc2ccccc2)C(=O)NC(C)C(=O)OC)cc1</smiles><smiles>C#Cc1ccc(C(=O)NC(C)C(=O)NC(Cc2ccccc2)C(=O)OC)cc1</smiles><smiles>C#Cc1ccc(C(=O)NC(CC(C)=CC)C(=O)N[C@@H](Cc2ccccc2)C(=O)OC)cc1</smiles>
$\mathrm{m}-(L, D)$-Phe-Phe-OMe (10)<smiles>[Y]C(C)=C(C)/C(C)=C\C(=O)c1ccc(C(=O)N[C@@H]([R])C(=O)NC([R])C(=O)OC)cc1</smiles>

Figure 2. (a) Monomer structures (1-10). (b) General PPA structures.

Thus, monomers (1-10) were prepared using peptide synthesis in solution and polymerized with $[\mathrm{Rh}(\mathrm{nbd}) \mathrm{Cl}]_{2}$ as catalyst $(\mathrm{nbd}=$ 2,5-norbornadiene), affording PPAs [poly-(1-10)] in good yields $(\approx 90 \%)$ and with a high content of the cis configuration of the double bonds (see SI for full details).
CD studies of poly-(1-3) - containing single alanine (poly-1) or dialanine as pendants [i.e. poly-(2-3)], where the first alanine is always introduced in the $L$ configuration, while the second one is introduced in either $L$ or $D$ absolute configuration- show similar CD traces in $\mathrm{CHCl}_{3}$ and DMF, ( $M$ and $P$ helices, respectively), even though the absolute configuration of the second alanine residue differs in poly-2 and poly-3. These results suggest that the chirality of the second alanine does not play a role in the helical induction of the PPA, and moreover, the antilsyn equilibrium found in PPAs bearing a single amino acid as pendants can be extrapolated to a dialanine system (Figure 3ac).
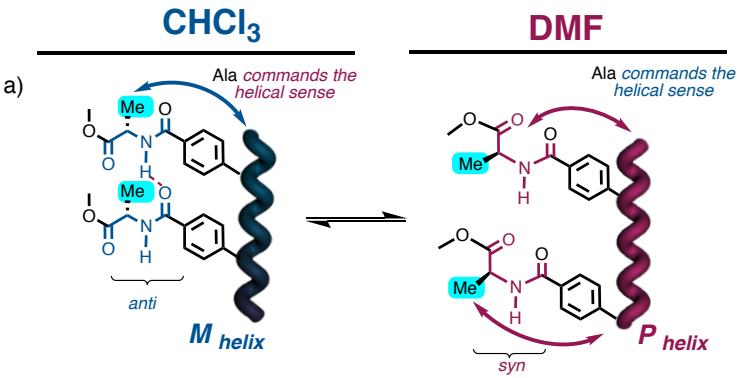

b)
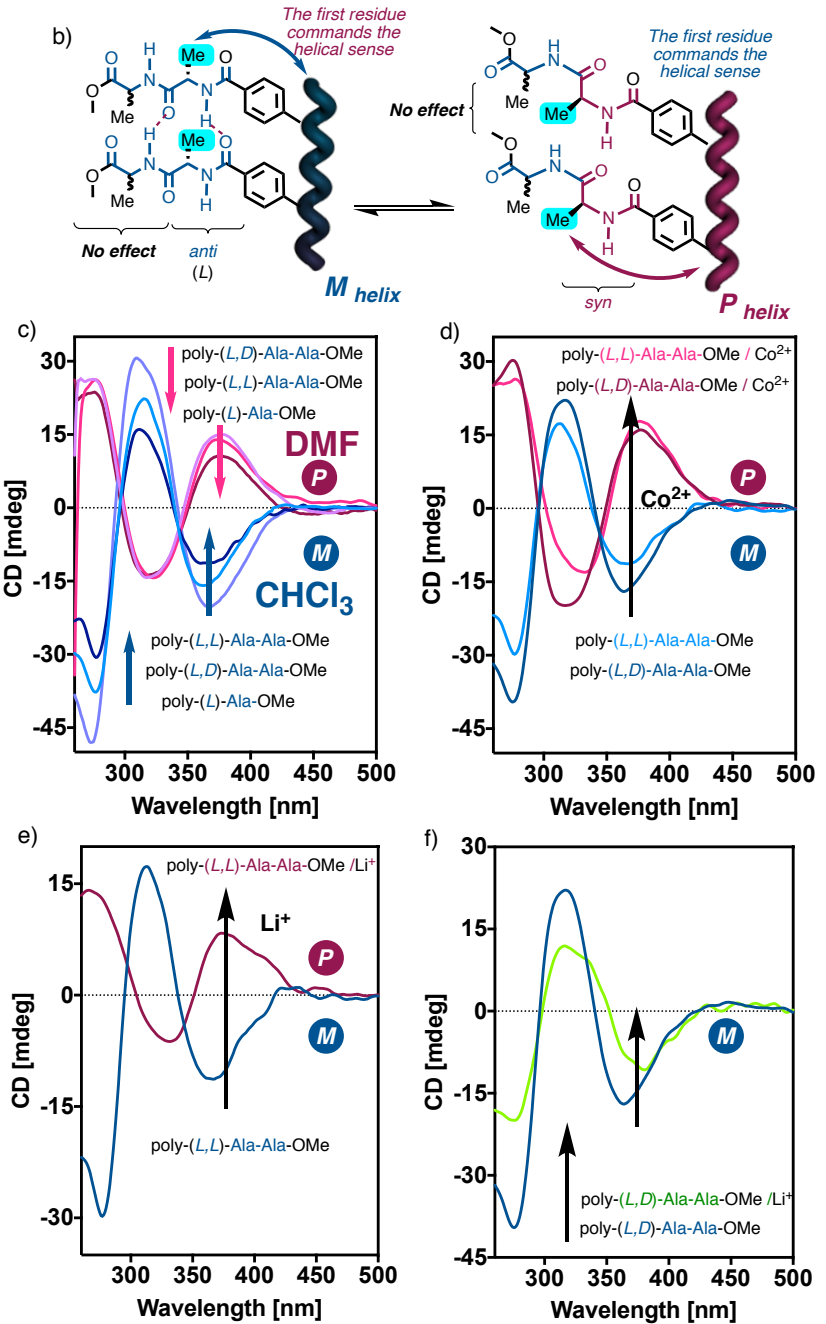

Figure 3. (a) Syn/anti conformational composition of poly-1 in DMF and $\mathrm{CHCl}_{3}$ (b) Syn/anti conformational composition of poly-(2-3). (c) CD spectra of poly(1-3) in DMF and $\mathrm{CHCl}_{3}$ (d) Helical inversion in a $\mathrm{CHCl}_{3}$ solution of poly-(2-3) by complexation with $\mathrm{Co}^{2+}$. CD spectra of (e) poly-2 and (f) poly-3 in $\mathrm{CHCl}_{3}$ before and after the addition of $\mathrm{LiClO}_{4}(50 \mathrm{mg} / \mathrm{mL})$. [Concn $=0.3 \mathrm{mg} / \mathrm{mL}$ ]. 
Next, we proceed to study the dynamic helical properties of these PPAs both in the presence and absence of cations as external stimuli. So, several metal ions dissolved in $\mathrm{MeOH}(50$ $\mathrm{mg} / \mathrm{mL}$ ) were added to the polymer solution $(0.3 \mathrm{mg} / \mathrm{mL})$. It was found that $\mathrm{Co}^{2+}$ can invert the helical structure of poly-(2-3) in $\mathrm{CHCl}_{3}$ due to an anti to syn shift of the conformational composition of the first residue of alanine produced by chelation with the metal ion (Figure 3d). ${ }^{[38]}$ On the other hand, the addition of $\mathrm{Li}^{+}$produces different results in poly-2 and poly-3, depending on the absolute configuration of the alanine residue placed at the remote position (second residue). Thus, while a helical inversion is obtained in poly-2 by the addition of $\mathrm{Li}^{+}$, poly-3 is not able to invert its helical structure, decreasing only its folding into a left-handed helical structure (Figure $3 \mathrm{e}, \mathrm{f}$ ).

In literature, we found that $\mathrm{Li}^{+}$can interact simultaneously with more than three different oxygen atoms in dipeptide/ $\mathrm{Li}^{+}$ complexes. ${ }^{[2-44]}$ Thus, a tripodal coordination of the metal ion to the dipeptide pendant can explain the abnormal effect observed when $\mathrm{Li}^{+}$is added. The formation of such a tripodal complex can force the two amino acid residues to adopt a syn conformation between carbonyls. This new spatial arrangement places the side chain of the alanine closer to the backbone and therefore affecting the helical sense of the PPA.

Thus, while in poly-2/Li+ methyls of first and second residues of alanine are oriented in the same direction, and therefore induce an analogous helix, in poly-3/Li ${ }^{+}$-poly- $(L, D)-A l a-A l a-O M e / \mathrm{Li}^{+}$- they are oriented in opposite directions. So, while the first residue induces a $P$ helix, the second one induces an $M$ helical structure, obtaining a combination of the two effects within the polymer chain, which results in a slight excess of an $M$ helical structure in the polymer metal complex. The coordination of lithium atoms to the three different carbonyl groups was further confirmed by IR (Figure 4a, $\mathrm{b}$ and Figures S39-40). a) poly-(L,L)-Ala-Ala-OMe / $\mathrm{Li}^{+}$

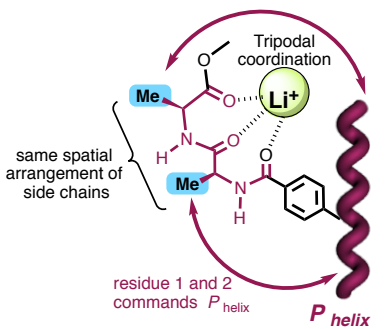

c) poly-(L,L)-Ala-Ala-OMe / $\mathrm{Co}^{2+}$

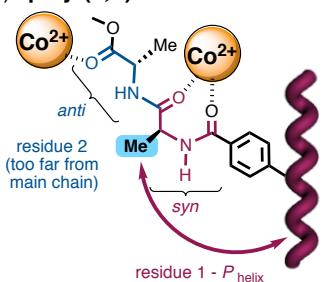

b) poly-(L,D)-Ala-Ala-OMe / $\mathrm{Li}^{+}$

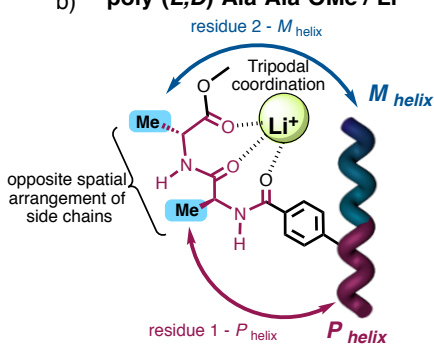

d)

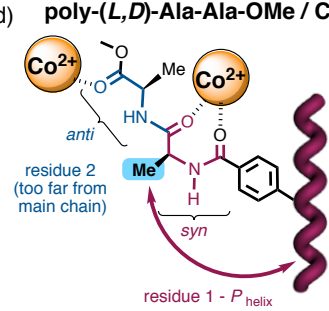

Figure 4. Suggested structures for: (a) poly-2/Li+, (b) poly-3/Li+, (c) poly-2/ $\mathrm{Co}^{2+}$ and (d) poly-3/Co ${ }^{2+}$.

In the case of poly-(2-3)/Co ${ }^{2+}$ complexes, IR studies indicate that $\mathrm{Co}^{2+}$ interacts with three carbonyl groups (Table S5, ESI). To explain the helical inversion in both helical polymer metal complexes, without influence of the absolute configuration of the second residue, we suggest that one of the $\mathrm{Co}^{2+}$ must chelate the two amide groups, inducing therefore a syn conformation at residue 1 , while another $\mathrm{Co}^{2+}$ coordinates the ester group leaving the residue 2 in anti-conformation. As a result, by using $\mathrm{Co}^{2+}$, the conformation stabilized at the dipeptide pendant group is analogous to the one obtained when the polymer is dissolved in polar solvents. The result in both cases is the adoption of a $P$ helix (Figure 4c, d and Figures S30, S31, S32).

Next, we decided to explore the role of the size of the substituents in the helical induction of a PPA bearing a dipeptide as pendant group. Thus, CD spectra of poly-(4-5) - [poly-(L,L)Ala-Phe-OMe, (poly-4); poly-(L,D)-Ala-Phe-OMe, (poly-5)]were measured in different solvents. Interestingly, we could observe that in polar solvents (i.e., DMF), poly-(4-5) behave in the same way as poly-(1-3), which indicates that the first alanine, in a syn conformation, is the one that governs the helical sense (Figure 2a). Unexpectedly, when the same experiments were carried out in $\mathrm{CHCl}_{3}, \mathrm{CD}$ spectra showed that these dipeptides do not behave as the previous ones — poly-(1-3)—. The ICD signals of poly-(4-5) in the vinyl region $(\approx 370 \mathrm{~nm})$ are weak, suggesting the presence of different conformations in equilibrium at the pendants (Figure 5a, b).
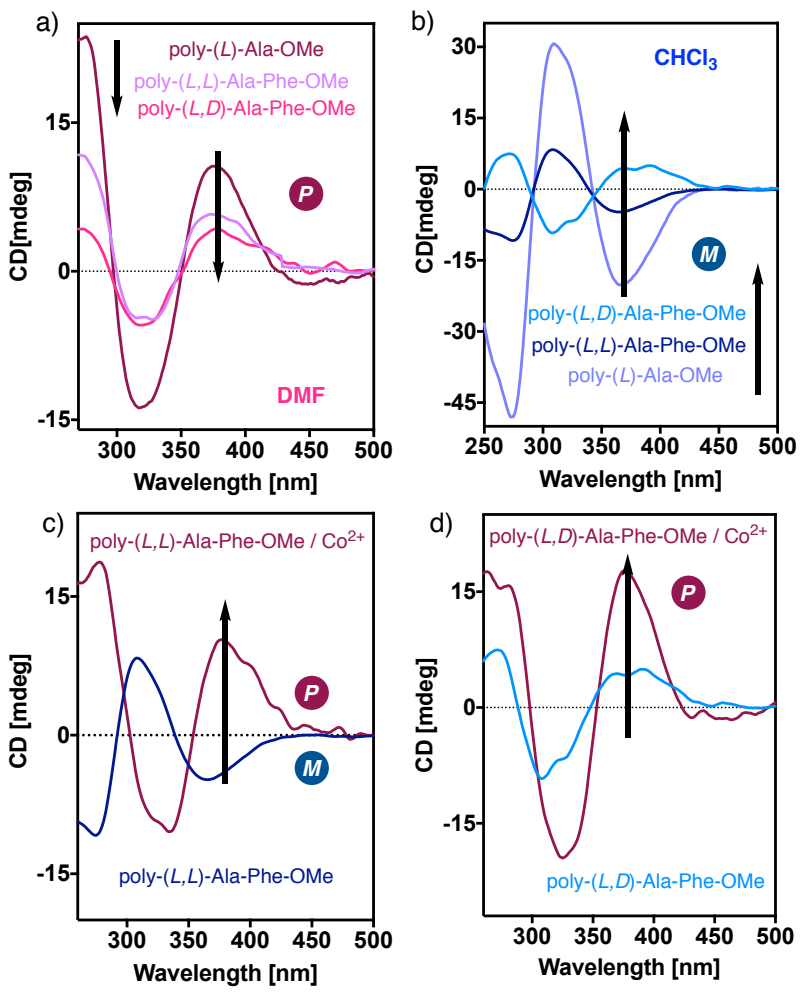

Figure 5. (a) CD spectra of poly-1 and poly-(4-5) in DMF and (b) $\mathrm{CHCl}_{3}$. (c-d) $\mathrm{CD}$ spectra of poly-(4-5) before and after the addition of $\mathrm{Co}\left(\mathrm{ClO}_{4}\right)_{2}$. [Concn= $0.3 \mathrm{mg} / \mathrm{mL}$ ]

Addition of metal ions as external stimuli reveals very interesting structural effects in the polymer. The addition of $\mathrm{Co}\left(\mathrm{ClO}_{4}\right)_{2}$ into a $\mathrm{CHCl}_{3}$ solution of poly-(4-5) induces the formation of a $P$ helix, in a similar way to the poly-(1-3)/Co ${ }^{2+}$ complexes, and suggesting an analogous mechanism (Figure $5 \mathrm{c}, \mathrm{d}$ ).

Interestingly, when $\mathrm{LiClO}_{4}$ is added to a $\mathrm{CHCl}_{3}$ solution of poly(4-5), a dual effect is observed controlled by the presence of a cosolvent $(\mathrm{MeOH})$ (Figure 6a, b). In the presence of a small 
amount of $\mathrm{MeOH}$ (5 equiv per monomeric repeating unit equiv), an $M$ helical structure is generated in poly-4 and poly-5, suggesting the induction of an ap conformation at the pendant group, similar to the one obtained for poly-(2-3) in low polar solvents, and where the chirality of the second residue does not play a role in the helical induction. ${ }^{7} \mathrm{Li}-\mathrm{NMR}$ experiments indicate that the anti conformation is stabilized by the formation of a cation- $\pi$ interaction (Figure $6 \mathrm{c}-\mathrm{h}$ ). ${ }^{[37,40,45]}$ Ulterior additions of methanol (> 225 equiv) disrupt the cation- $\pi$ interaction. The coordination mode of the $\mathrm{Li}^{+}$towards the pendant group changes to a tripodal coordination in a similar way as the one described previously for poly-(2-3)/Li+
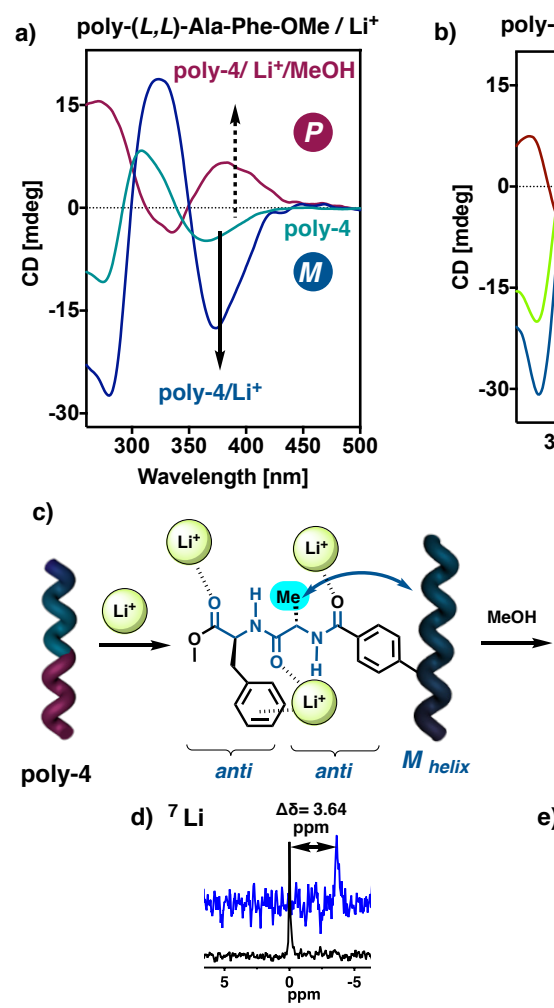

b) poly-(L,D)-Ala-Phe-OMe $/ \mathrm{Li}^{+}$
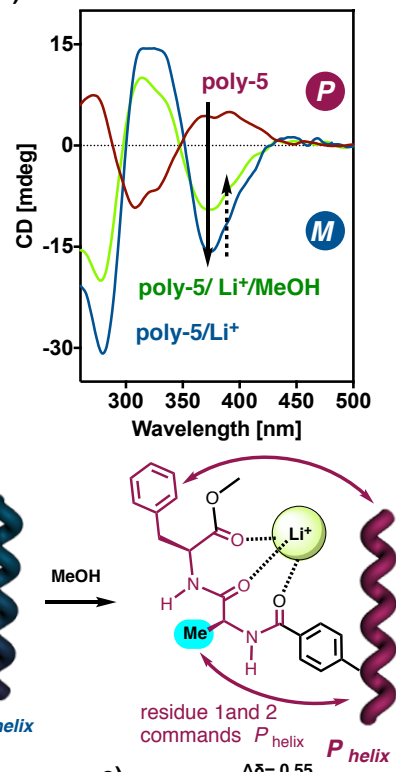

e) ${ }^{7} \mathrm{Li}$

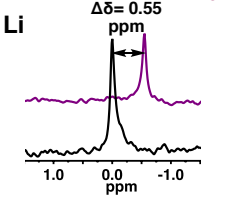

f)
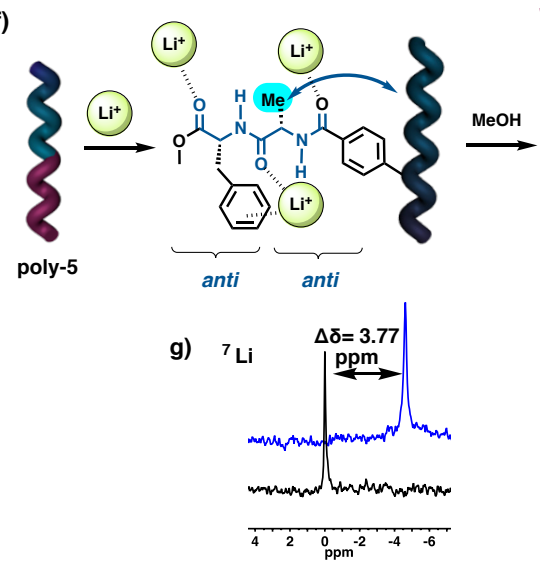

residue 2
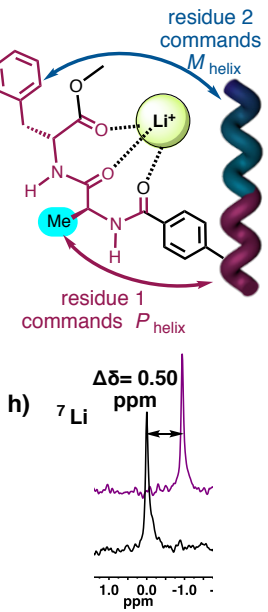

Figure 6. (a) $\mathrm{CD}$ spectra of poly-4 and (b) poly-5 in $\mathrm{CHCl}_{3}$ before and after the addition of $\mathrm{LiClO}_{4}$. (c) Suggested structures for poly-4/Li ${ }^{+}$and ${ }^{7} \mathrm{Li}-\mathrm{NMR}$ experiments before (d) and after (e) disruption of the cation- $\pi$ interaction by addition of $\mathrm{MeOH}$. (f) Suggested structures for poly-5/Li+ and ${ }^{7} \mathrm{Li}-\mathrm{NMR}$ experiments before $(\mathrm{g})$ and after $(\mathrm{h})$ disruption of the cation- $\pi$ interaction by addition of $\mathrm{MeOH}$. [Concn $=0.3 \mathrm{mg} / \mathrm{mL}$ ].
In a new design, we switched positions between alanine and phenylalanine residues at the dipeptide pendant. These new PPAs - [poly-(L,L)-Phe-Ala-OMe (poly-7); poly-(L,D)-Phe-AlaOMe, (poly-8)] - allowed exploring how the size of the different substituents affect both the helical structure and the dynamic behaviour of the PPAs. In previous systems - poly-(4-5)-, the largest amino acid residue was placed in a remote position (second residue), being now, in this new design, closer to the polyene scaffold (as first residue).

CD studies of poly-6 - (poly-(L)-Phe-OMe) used as controland poly-(7-8) in polar and low-polar solvents show that when a second amino acid -in this case alanine - is coupled to a phenylalanine residue, the helical folding of the PPA is almost lost. This fact is due to the presence of several conformations in equilibrium at the dipeptide pendant (Figures 7a, b).
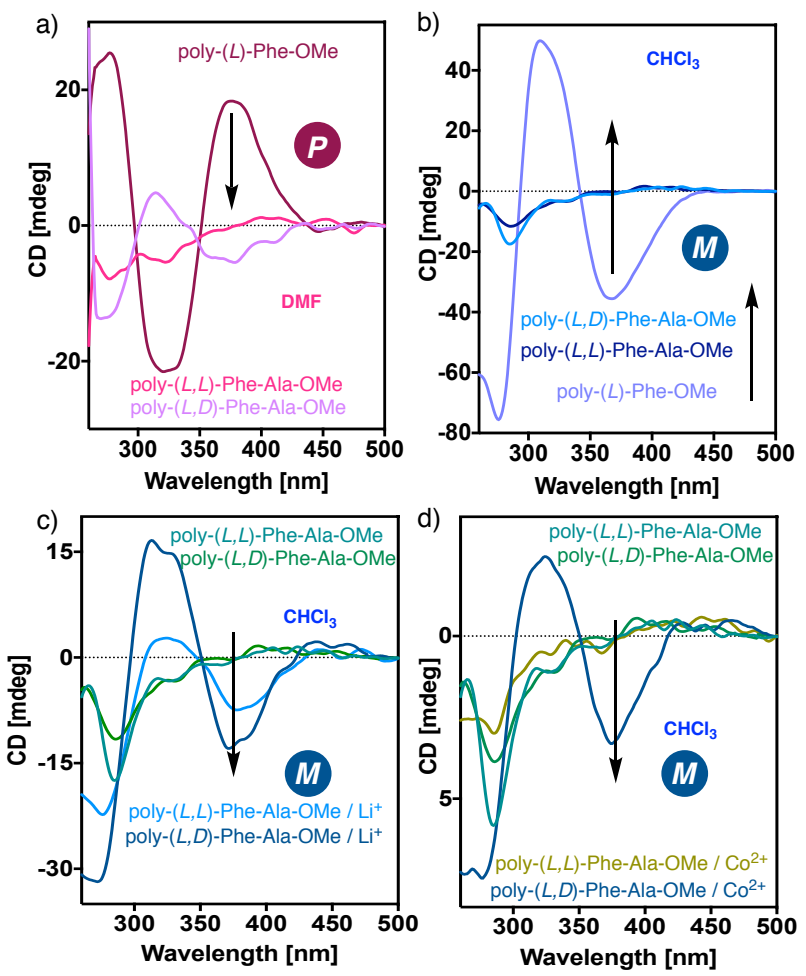

e)
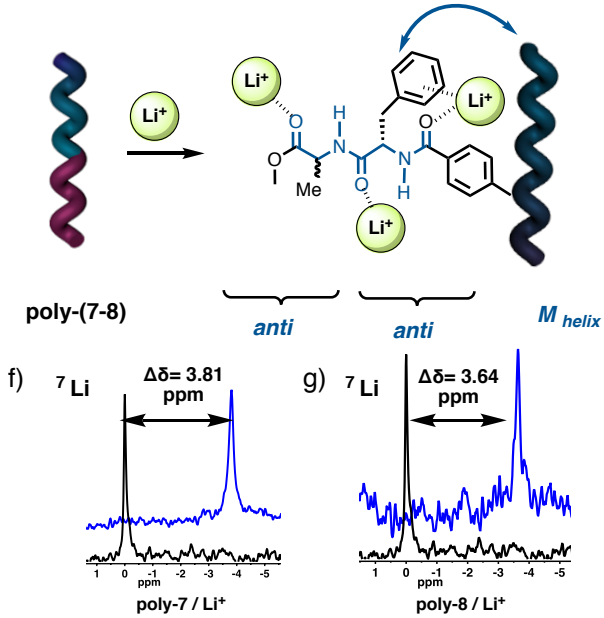

Figure 7. (a) CD spectra of poly-7 and poly-8 in DMF and (b) $\mathrm{CHCl}_{3}$. (c) $\mathrm{CD}$ spectra of poly-(7-8) in $\mathrm{CHCl}_{3}$ before and after the addition of $\mathrm{LiClO}_{4}$ and (d) $\mathrm{Co}\left(\mathrm{ClO}_{4}\right)_{2}$. (e) Suggested structures for poly-7/Li+ and poly-8/Li+ ${ }^{+}$(f) ${ }^{7} \mathrm{Li}-\mathrm{NMR}$ spectra confirming the cation- $\pi$ interaction in poly-7 and $(\mathrm{g})$ poly-8. 
Next, we decided to stabilize a conformation at the dipeptide fragment by adding metal ions and to induce a single-handed helix in the polymer. We found that $\mathrm{Li}^{+}$can only stabilize the anticonformation at the pendant group through cation- $\pi$ interactions, although no evidence of tripodal syn conformation was obtained by titration of the poly-(7-8)/Li ${ }^{+}$complexes with methanol (Figure 7c, e-g and Figures S35a, S36a). Moreover, other metal ions such as $\mathrm{Co}^{2+}$-that induces in the previous cases a syn conformation of the alanine residue- cannot form a similar complex when phenylalanine is occupying that position. In addition, the metal ion interaction only occurs for poly-8, indicating that in this case the absolute configuration of the second chiral center does play a role in the PPA interaction with metal ions (Figure 7d and Figures S35d, S36d).

Finally, we decided to study a PPA bearing a diphenylalanine dipeptide as pendant group to complete the PPA dipeptide series [poly-(L,L)-Phe-Phe-OMe (poly-9); poly-(L,D)-Phe-PheOMe, (poly-10)]. In this case, CD studies in polar and low polar solvents show again that these PPAs are highly dynamic. In $\mathrm{CHCl}_{3}$, a $\mathrm{CD}$ signal is obtained in both cases at $280 \mathrm{~nm}$ corresponding to the pendant chirality but not to a PPA helical structure. On the other hand, in polar solvents the presence of an excess of a left-handed helix is observed (Figure 8a). Addition of $\mathrm{LiClO}_{4}$ to a $\mathrm{CHCl}_{3}$ solution of poly-(9-10) produces a similar response to poly-(7-8)/Li complex, the induction of $M$ helix due to the presence of all anti conformations at the pendants, in this case stabilized by cation- $\pi$ interactions as determined by ${ }^{7}$ Li-NMR (Figure 8b, c and Figures S45, S46).

Other metals such as $\mathrm{Co}^{2+}$, that interacts better with the PPA when alanine is the first residue of the dipeptide in poly-(2-5), are not able to produce any responses in poly-(9-10). This outcome indicates that formation of the syn conformer in bulky amino acids is less favored (Figures S37, S38).

$A$ remarkable and unexpected result was obtained when $\mathrm{Ba}^{2+}$ was added as external stimulus. In this case, the two PPAs poly(9-10) induce opposite helical senses when interact with this metal ion (Figure 8d). This result indicates that the residue that governs the helical sense is residue 2, the one placed at the remote position. IR studies indicate that the metal ion coordinates only residue 2 , the one that governs the helical sense (Figures S47, S48). This fact is probably due to the larger size of the metal ion.

To have an effective helical induction from a remote chiral center, surpassing the chiral information from the closest chiral center, it is necessary for the dipeptide pendant to adopt a bent structure. By doing this, the second amino acid is placed spatially closer to the polyene backbone. Therefore, a reasonable mechanism of helical induction in these systems is shown in Figure $8 \mathrm{e}, \mathrm{f}$.

\section{Conclusion}

We have demonstrated that PPAs bearing pendant groups with more than one chiral center adopt a helical sense induced by the chiral center placed in a closer spatial position to the polyene backbone. This center does not have to be coincident with the first chiral residue in the sequence of the pendant. We have prepared PPAs bearing diphenylalanine dipeptide pendants whose helical sense, when interacting with $\mathrm{Ba}^{2+}$, is governed by the chirality of the phenylalanine located in the remote position. So, poly- $(L, L)-P h e-P h e-O M e / \mathrm{Ba}^{2+}$ adopts an $M$ helix, while poly-
$(L, D)$-Phe-Phe-OMe/Ba ${ }^{2+}$ adopts a $P$ helix. These results demonstrate that the chiral order commanded by a chiral residue directly linked to the backbone can be surpassed by another chiral center in a spatially closer position to the polyene main chain. This is a very interesting phenomenon in dynamic helical polymers that can have potential applications in fields such as sensing, chiral stationary phases or asymmetric synthesis, among others.
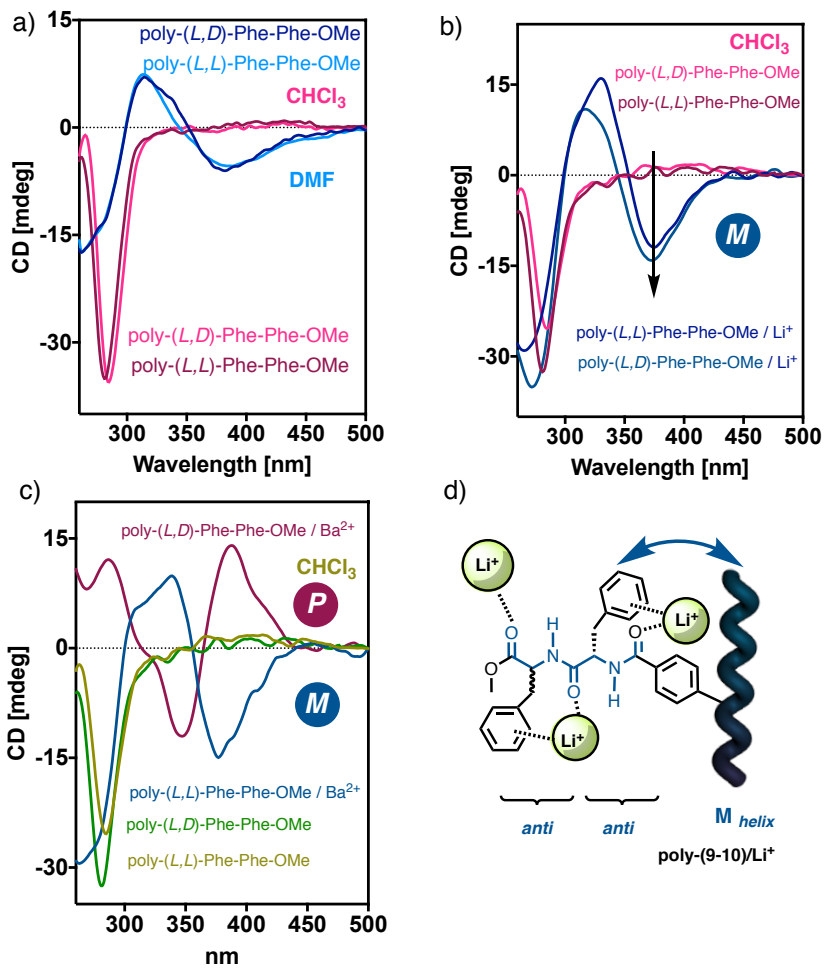

d)
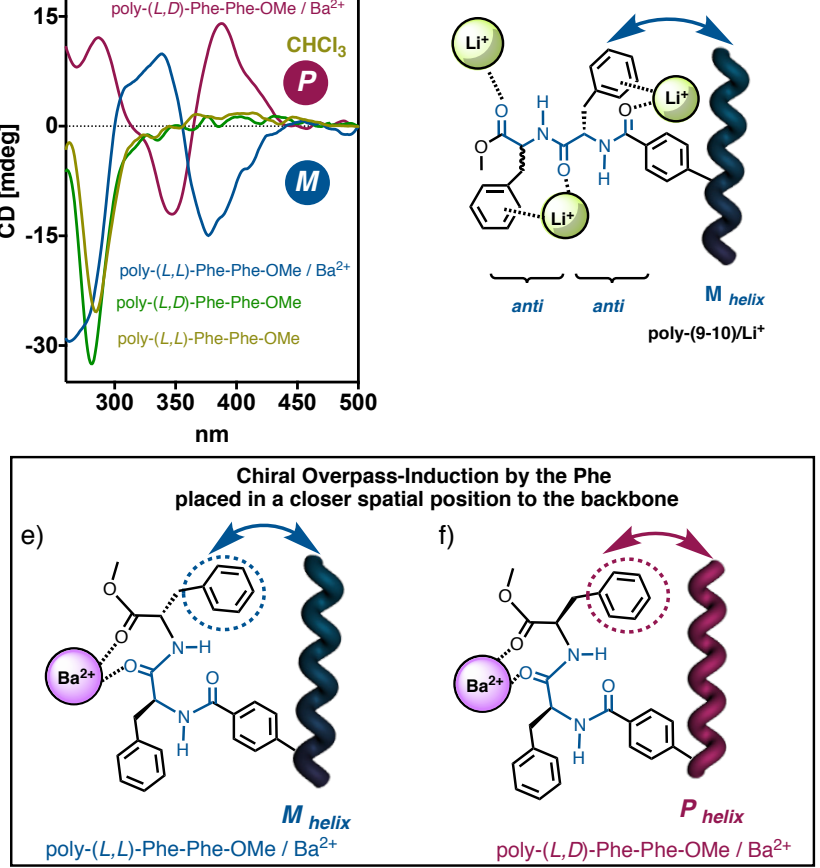

Figure 8. (a) CD spectra of poly-(9) and poly-(10) in DMF and $\mathrm{CHCl}_{3}$. (b) $\mathrm{CD}$ spectra of poly-(9-10) before and after the addition of $\mathrm{LiClO}_{4}$ and (c) $\mathrm{Ba}\left(\mathrm{ClO}_{4}\right)_{2}$. (d) Suggested structures for poly- $(L, L)-P h e-P h e-O M e / L^{+}$and poly- $(L, D)-P h e-$ Phe-OMe/Li+ (e) Suggested structures for poly-(L,L)-Phe-Phe-OMe/Ba ${ }^{2+}$ and (f) poly- $(L, D)-\mathrm{Phe}-\mathrm{Phe}-\mathrm{OMe} / \mathrm{Ba}^{2+}$ showing the chiral overpass-induction phenomena.

\section{Acknowledgements}

Financial support from MINECO (CTQ2014-61470-EXP, CTQ2015-70519-P), Xunta de Galicia (ED431C 2018/30, Centro singular de investigación de Galicia accreditation 2016-2019, ED431G/09) and the European Regional Development Fund (ERDF) is gratefully acknowledged. E. S. P. is grateful to MEC for a FPU predoctoral fellowship. 
Keywords: cation- $\pi \cdot$ circular dichroism $\cdot$ chirality $\cdot$ chiral overpass-induction $\cdot$ helical polymers $\cdot$ helical sense • poly(phenylacetylene)s

[1] Yashima, E.; Ousaka, N.; Taura, D.; Shimomura, K.; Ikai, T.; Maeda, K. Chem. Rev., 2016, 116, 13752-13990.

[2] Yashima, E.; Maeda, K.; Furusho, Y. Acc. Chem. Res. 2008, 41, 11661180.

[3] Yashima, E.; Maeda, K.; lida, H.; Furusho, Y.; Nagai, K. Chem. Rev. 2009, 109, 6102-6211.

[4] Liu, J.; Lam, J. W. Y.; Tang, B. Z. Chem. Rev. 2009, 109, 5799-5867.

[5] Rosen, B. M.; Wilson, C. J.; Wilson, D. A.; Peterca, M.; Imam, M. R.; Percec, V. Chem. Rev. 2009, 109, 6275-6540.

[6] Schwartz, E.; Koepf, M.; Kito, H. J.; Nolte, R. J. M.; Rowan, A. E. Polym. Chem. 2011, 2, 33-47.

[7] Anger, E.; lida, H.; Yamaguchi, T.; Hayashi, K.; Kumano, D.; Crassous, D.; Vanthuyne, N.; Rousselc, C.; Yashima, E. Polym. Chem. 2014, 5, 4909-4914.

[8] lida, H.; Miki, M.; Iwahana, S.; Yashima, E. Chem. Eur. J. 2014, 20, 4257-4262.

[9] Leiras, S.; Freire, F.; Seco, J. M.; Quiñoá, E.; Riguera, R. Chem. Sci. 2013, 4, 2735-2743.

[10] Sakurai, S.; Okoshi, K.; Kumaki, J.; Yashima, E. J. Am. Chem. Soc. 2006, 128, 5650-5651.

[11] Okoshi, K.; Sakurai, S.; Ohsawa, J. K.; Yashima, E. Angew. Chem. Int. Ed. 2006, 45, 8173-8176.

[12] Pijper, D.; Jongejan, M. G. M.; Meetsma, A.; Feringa, B. L. J. Am Chem.Soc. 2008, 130, 4541-4552.

[13] Thodupunuri, P.; Katukuri, S.; Ramakrishna, K. V.; Sharma, G.; Kunwar, A. C.; Sarma, A.; Hofmann, H. J. Org. Chem, 2017, 82, 2018-2031.

[14] Feringa, B. L. Acc. Chem. Res. 2001, 34, 504-513.

[15] Suárez-Picado, E.; Quiñoá, E.; Riguera, R.; Freire, F. Chem. Mater. 2018, 30, 6908-6914.

[16] Shimomura, K.; Ikai, T.; Kanoh, S.; Yashima, E.; Maeda, K. Nat. Chem., 2014, 6, 429-434.

[17] Burgess, M.; Moore, J. S.; López, J. R. Acc. Chem. Res. 2016, 49 , 2649-2657.

[18] lida, H.; Tang, Z.; Yashima, E. J. Polym. Sci., Part A: Polym. Chem. 2013, 51, 2869-2879.

[19] Tang, Z.; lida, H.; Hu, H.-Y.; Yashima, E. ACS Macro Lett. 2012, 1,261265.

[20] Megens, R. P.; Roelfes, G. Chem. Eur. J. 2011, 17, 8514-8523.

[21] Liu, X.; Lin, L.; Feng, X.. Acc. Chem. Res., 2011, 44, 574-587.

[22] lida, H.; Yashima, E., Polymeric Chiral Catalyst Design and Chiral Polymer Synthesis, ed. Itsuno, S., John Wiley \& Sons, Hoboken, NJ, USA, 2011, ch. 7, p 201.

[23] Cornelissen, J. J. L. M.; Rowan, A. E.; Nolte, R. J. M.; Sommerdijk, N. A. J. M. Chem. Rev., 2001, 101, 4039-4070.

[24] Cornelissen, J. J. L. M.; Donners, J. J. J. M.; de Gelder, R.; Graswinckel, W. S.; Metselaar, G. A.; Rowan, A. E.; Sommerdijk, N. A J. M.; Nolte, R. J. M. Science, 2001, 293, 676-680.

[25] Kamikawa, Y.; Kato, T.; Onouchi, H.; Kashiwagi, D.; Maeda, K.; Yashima, E. J. Polym. Sci. A Polym. Chem., 2004, 42, 4580-4586.

[26] Maeda, K.; Tsukui, H.; Matsushita, Y.; Yashima, E. Macromolecules, 2007, 40, 7721-7726.

[27] Cornelissen, J. J. L. M.; Graswinckel, W. S.; Adams, P. J. H. M.; Nachtegaal, G. H.; Kentgens, A. P. M.; Sommerdijk, N. A. J. M.; Nolte, R. J. M. J. Polym. Sci., Part A: Polym. Chem. 2001, 39, 4255-4264.

[28] Ramos, E.; Bosch, J.; Serrano, J. L.; Sierra, T.; Veciana, J. J. Am. Chem. Soc. 1996, 118, 4703-4704.

[29] Amabilino, D. B.; Ramos, E.; Serrano, J. L.; Sierra, T.; Veciana, J. J. Am. Chem. Soc., 1998, 120, 9126-9134.

[30] Maeda, K.; Kamiya, N; Yashima, E. Chem. Eur. J. 2004, 10, 4000-4010.

[31] Arias, S.; Freire, F.; Calderón, M.; Bergueiro, J. Angew. Chem. Int. Ed., 2017, 56, 11420-11425.

[32] Rodríguez, R.; Quiñoá, E.; Riguera, R.; Freire, F. Chem. Mater. 2018, $30,2493-2497$.
[33] Rodríguez, R.; Quiñoá, E.; Riguera, R.; Freire, F. Small, 2019, 15, 1970070.

[34] Louzao, I.; Freire, F.; Seco, J. M.; Quiñoá, E.; Riguera, R. Angew. Chem. Int. Ed., 2010, 49, 1430-1433.

[35] Freire, F.; Seco, J. M.; Quiñoá, E.; Riguera, R. Angew. Chem., Int. Ed. 2011, 50, 11692-11696.

[36] Freire, F.; Seco, J. M.; Quiñoá, E.; Riguera, R. J. Am. Chem. Soc. 2012 134, 19374-19383.

[37] Arias, S.; Freire, F.; Quiñoá, E.; Riguera, R. Angew. Chem., Int. Ed. 2014, 53, 13720-13724

[38] Arias, S.; Freire, F.; Quiñoá, E.; Riguera, R. Polym. Chem. 2015, 6, 4725-4733.

[39] Arias, S.; Núñez-Martínez, M.; Quiñoá, E.; Riguera, R.; Freire, F. Polym. Chem. 2017, 8, 3740-3745.

[40] Rodríguez, R.; Arias, S.; Quiñoá, E.; Riguera, R.; Freire, F. Nanoscale 2017, 9, 17752-17757.

[41] Alzubi, M.; Arias, S.; Quiñoá, E.; Riguera, R.; Freire, F. Chem. Commun. 2017, 53, 8573-8576.

[42] Müller, G.; Maier, G-M.; Lutz, M. Inorganica Chim. Acta, 1994, 218, 121-131.

[43] Dudev, T.; Mazmanian, K.; Lim, C. Chem. Sci. 2018, 9, 4093-4103.

[44] Izatt, R. M.; Bradshaw, J. S.; Dalley, N. K. Chem. Rev. 1991, 91, 137164.

[45] G. Wu; V. Terskikh. J. Phys. Chem. A. 2008, 112, 10359-10364. 


\section{TOC}

2 comands the helical sense

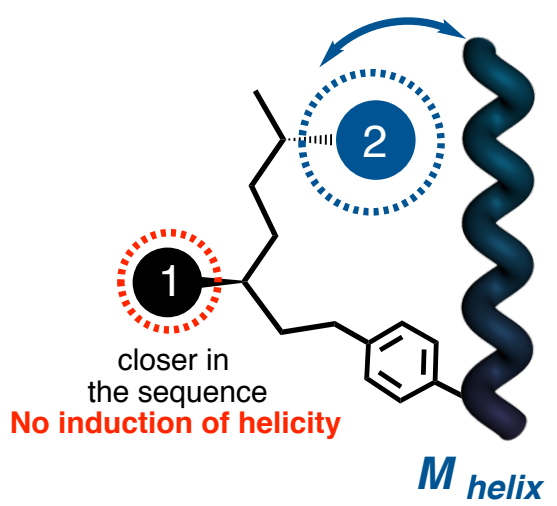

2 comands the helical sense

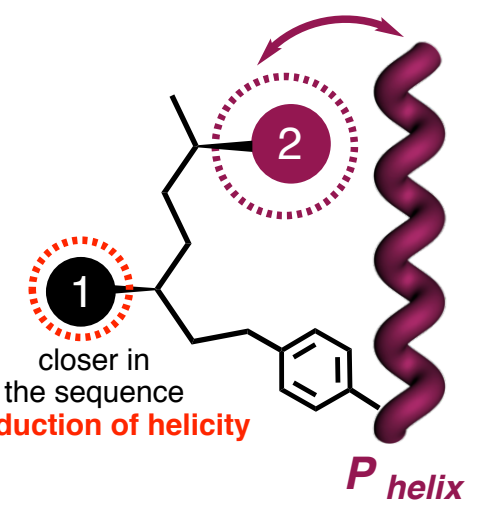

